\title{
Moon: A Sensuous Scholarship of the Art of Costume Breakdown in Film
}

Harriet Parry December 2017

Published edition: Parry, H. 2017, "Moon: A sensuous scholarship of the art of costume breakdown in film", Film, Fashion \& Consumption, vol. 6, no. 2, pp. 89-103

\begin{abstract}
:
Cloth has a particular relationship with the human body. As clothing it is always in contact with, or imagined to be in contact with the skin, our largest sense organ. Cloth is our interface with the outside world, and the way in which we cover that interface has meaning. The important relationship we have with cloth to protect and augment our bodies performs as a prosthesis of touch that, in its everydayness, offers constant opportunity for expression and fetishization within the various discourses of identity in art, fashion and lifestyle. This paper looks to explore the way in which cloth as costume in the medium of film, having been 'broken down' to naturalise the piece to its setting, stimulates an embodied relationship between the audience, the actor and the film itself. Following Laura Marks and her theories on visual haptics the piece is a sensuous scholarship of an often overlooked and under researched textile art whose affect, the paper argues, is that of reinstating the 'aura' that Walter Benjamin stated is lost by the mechanical intervention of the movie camera.
\end{abstract}

Key-Words: costume, breakdown, phenomenology, haptic visuality, rubrics, aura, sensuous scholarship, folds. 
Cloth as a utilitarian material object has multiple uses to become garments, cover furnishings or perform as an artist's medium and all these uses have a particular relationship with the human body. It is always in contact with, or imagined to be in contact with the skin, our largest sense organ. Our skin encases our bodies with a complex structure that insulates and excretes to keep our system in balance. It is our interface with the outside world, and the way in which we cover that interface has meaning. As Claire Pajaczkowska explains: - '[w]e intuit the significance of wrapping as a prosthesis of touch, the continued existence of the hand in the absence of the body that offers touch' (Pajaczkowska 2005: 223). The important relationship we have with cloth as a prosthesis of touch, in its everydayness, offers constant opportunity for expression and fetishisation within the various discourses of identity in art, fashion and lifestyle. The statements made by clothing as costume and its discourse with the audience within the medium of film, have been much explored. Decisions made by the costume designer about the ways in which costume supports the film's narrative and its relationship with the actor wearing it are important when analysing the intertextuality of the medium with the cultural discourses that have informed the designs. Academics such as Gaines and Herzog (1990) and Bruzzi (1997) for example, offer valuable insights into the various roles costume can play within film narrative and construction of character identity.

This essay however, aims to move beyond the semantic meanings that a particular costume might communicate, and analyse the possible pre-symbolic, interoceptive (Sobchack 1990: 22) phenomenological effects that particular manipulations of those costumes through the textile art of 'costume breakdown' might have on the audience. The costume can be changed significantly by the textile artist by being augmented with textures and colours or diminished and worn away to fit the narrative of the film. When watching a film, we cannot touch with our hands, we must touch with our eyes, we must use what Laura Marks describes as 'haptic visuality' (Marks 2000: 162) to feel the cloth depicted, and by extension the person whose skin is touched by that cloth. Costume represents what Pajaczkowska describes as the 'most thoughtful of human actions, to cover, conceal, protect, display and shroud' (Pajaczowska 2005: 235). Its design describes narratives of the character's very being, performing as a "second skin" (Pajaczowska: 235). Costume breakdown is often used to visually represent or further emphasise the internal world of the character it covers. The term 'breaking down' infers something that has been embattled, beaten, wrestled to submission. In the artist's workshop the fabric is often forced to undertake many years of wear and tear in the space of a few hours. The fabric is anthropomorphised, activated, performative as prosthesis for the skin 
that is covered, the body and this activity gives life and volatility to the fabric. Placing the cloth in a liminal space that makes us question its 'thingness'. Elizabeth Grosz describes the body as a "most peculiar "thing," for it is never quite reducible to being merely a thing; nor does it ever manage to rise above the status of thing' (Grosz 1994: xi). The thingness of the cloth that covers acts in proxy for the thingness of the body.

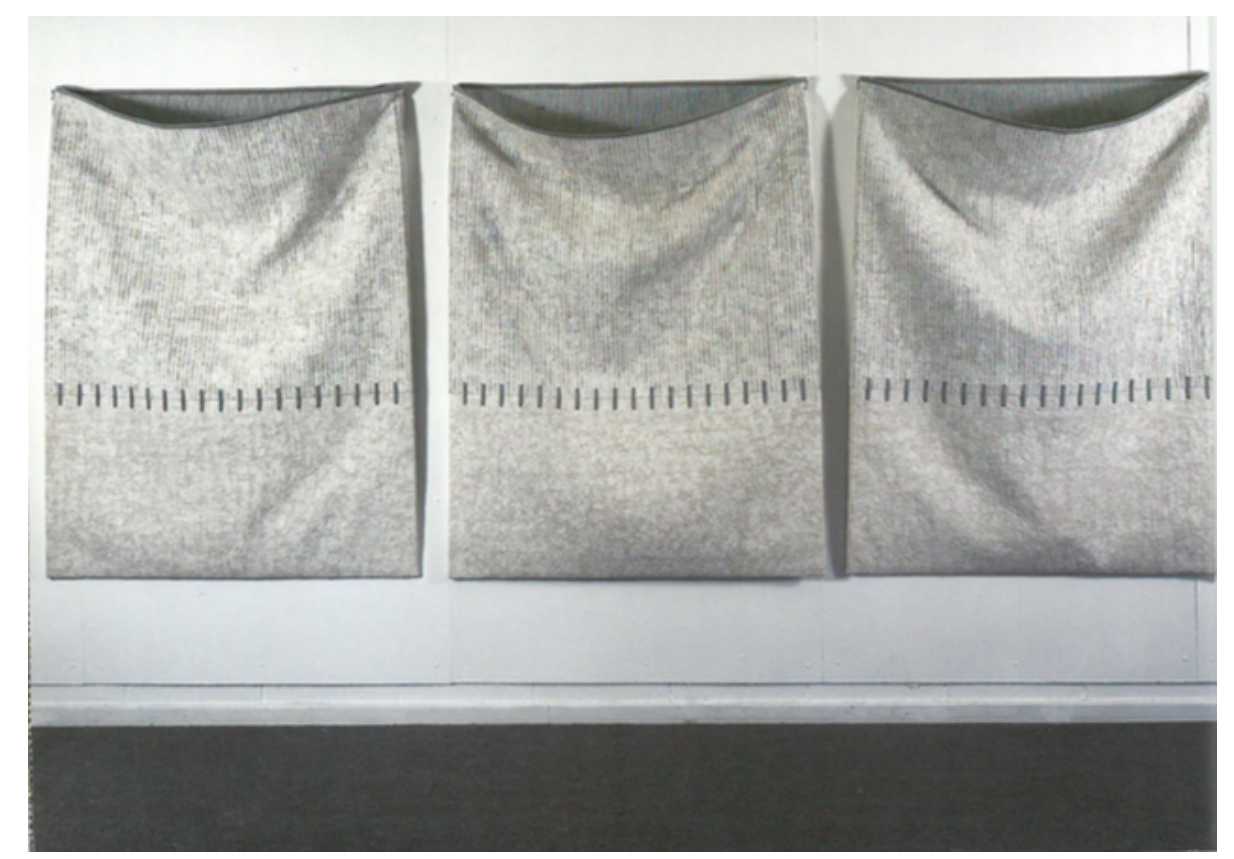

Figure 1: Maxine Bristow, Intersecting a Seam, 1998. Linen cotton and gesso. $3 \times 19$. From the Exhibition: Textures of Memory The Poetics of Cloth () Maxine Bristow

I suggest that Maxine Bristow, in her artwork Intersecting the Seam (Fig.1) offers an example of how a piece of cloth, being treated in much the same way as a textile artist might break down a costume, has created a 'thing' that represents the corporeal 'thingness' of the body itself. Constructed like a pocket that seems to have been full, the open weave of the cloth, the intervention of the stitching, the ingrained shading of the paint, offers meaning that I suggest we read in the same way as we might read the textures of textile manipulation in film, or 'the sensation that is painted' (Deleuze 2005;2003: 35). Deleuze in his masterwork on the phenomenology of Francis Bacon's painting, explores the visceral affects some paintings have on our bodies and their ability to be the corporeal, interoceptive sensations that they stimulate.

What is painted on the canvas is the body, not insofar as it is represented as an object, but insofar as it is experienced as sustaining this sensation (Deleuze 2005;2003: 35). 
As a platform for my analysis of the art of costume breakdown, and the sensations it might embody, I will focus on the film Moon (2009), devised and directed by Duncan Jones, the costumes designed by Jane Petrie. My belief is that Moon, with Petrie's well-crafted realistic designs, sympathetically broken down, contains a complexity of costume discourse within a single, uncluttered setting of a Moon base, that offers interesting opportunities for analysis. I hope to unpick how we might commonly relate to the 'thingness' of the textile's surfaces that we gaze upon. What theories might be useful in approaching an analysis of this particular mode of haptic communication through costume? What might be happening in the seconds before any culturally semiotic readings are made? And how might these technologies affect the way a film is experienced?

Taking advice from anthropologist Paul Stoller, my approach will be a form of Sensuous Scholarship (Stoller, 1997), following theorists such as Deleuze and Merleau-Ponty. Laura Marks, Claire Pajaczkowska and Vivian Sobchack have also been instrumental in guiding my analysis of what I see, and how others might see the same. It may be that as a costumer, and craftsperson who has spent many years working in film, my scholarship of material objects will be predisposed to the sensuous nature of the object. When viewing a film, it will be with a haptic gaze, seeking out tactility as a particular personal lexia (Barthes 1977: 33). I must acknowledge that some viewers may be more predisposed than others to view these images haptically (Marks 2000: 170). I believe however, that costume breakdown can aid those who do not generally see haptically by accentuating, and changing the surface of the cloth, manipulating the way that light plays across the surface of the textile, sending enriched messages to the retina.

Costume breakdown is principally the responsibility of skilled craftspeople who could be known as a 'textile artists', 'breakdown artists' or 'art finishers'. They will collaborate with the design team to naturalise the costumes to fit within the fabricated realities of film, television and theatre. The work could involve dyeing the fabric and the design and print of patterns before being taken to the costume makers, or treating it to various forms of 'breakdown' once the costumes have been made. As would any artist well versed with a particular medium, in order to successfully manipulate the cloth, they must have an understanding of the nature of a particular textile, its physical properties and the way it might hold paints or withstand certain treatments such as vigorous washing, dyeing, spraying, bleaching and wearing. Vital in their role is the 'life' that they imbue within the item of 
clothing. How has the character lived? How do they feel? What are their habits? They must embody the costume before it has even been worn. Pajaczkowska believes that 'the textile arts, more than any other, implicate the body as corporeal reality' (Pajaczkowska: 223). Peter Stallybrass in his analysis of Marx's coat eloquently describes the evidence of the signs of wear of a garment subjected to everyday life that costume breakdown attempts to replicate.

In the language of the nineteenth century clothes-makers and repairers, the wrinkles in the elbows of a jacket or sleeve were called "memories." Those wrinkles recorded the body that had inhabited the garment. They memorized the interaction, the mutual constitution, of person and thing (Stallybrass 1998: 133).

The 'memories' in Marx's coat devalued it as a commodity when presented to the pawnbroker (Stallybrass:133). On screen the 'memories' imbued in costumes, are the embodied human traces that give authenticity to a character. The audience reads the signifiers offered and this discourse enables an understanding of the character before they have even spoken, a reading that most of us subconsciously undertake during our everyday interactions with one another. Merleau-Ponty states:

It is true in our ordinary lives we lose sight of the aesthetic value of the tiniest perceived thing. It is also true that the perceived form is never perfect in real life, that it always has blurs, smudges and superfluous matter, as it were (Merleau-Ponty 1964: $58)$.

A skilled costume designer or textile artist, brings these details back into focus so that we are more able to make sense of the characters. To an extent there is an element of theatricality and exaggeration in the application of breakdown to the costume, with the advent of high definition cameras and ever higher definition projection, it may be that a subtler approach is required in application. Again a skill of the textile artist is understanding how the camera will read the surface of the cloth and the effect the play of light has on it. In the search for authenticity a deft hand applies the properties to cloth that we have learned to read without conscious acknowledgment in our daily lives. It is when that 'thingness' is missing from sight, or the application jars with the style of the film or narrative, that we begin to feel uncomfortable, something's not right with the world we are perceiving. We are less likely to suspend our reality and become immersed in the film and engage in its reality. 
Jane Petrie is a Scottish costume designer who prides herself on the realism that she brings to her work. On her personal website she outlines that ' $[\mathrm{t}]$ he work needs to be almost invisible, drawing the viewer into a belief in the reality of the created world' (Petrie 2017). She also outlines her approach to designing realism, she explains: -

Storytelling and character arcs are extremely subtle and need to speak in a highly sophisticated language because the viewer subconsciously operates within this language every day. There can be no clumsy statements, and unauthentic characters will be quickly spotted by a contemporary audience (Petrie, 2017).

Known for films such as Suffragette (Sarah Gavron, 2015) and Fish Tank (Andrea Arnold, 2009), she has an 'unusual amount of practical experience for a [costume]designer' (Petrie, personal communication, 2017). Having studied and practiced a rich variety of technical costume disciplines before designing her first film, this knowledge resonates onto the screen. Petrie's work in Moon offers a masterclass on how realism in costume design can be applied effectively to a Science Fiction fantasy, aided by the film's clear connection to a real, contemporary world that could be our own. Petrie warns however that care must be taken when making design decisions: - 'With Sci-Fi there is always the risk of blowing the conceit of the script if each department doesn't have logic to back up its design so things come up in prep that we have to consider very carefully' (Petrie, personal interview, 2017). Part of those design decisions are the ways in which costumes are broken down to be naturalised to a fabricated reality, a factor that art directors and set designers also need to consider in their approach to designing the film's environment. It might be worth considering at this point that when following my thesis on how costume breakdown might engage the audience, these ideas could be interesting to explore in the context of other on-screen design disciplines.

Moon, set in the not too distant future, tells the story of an astronaut 'Sam1', played by Sam Rockwell, who is coming to the end of a three-year stint working alone harvesting solar energy on the Moon's surface. He is tired and he misses his family, he seems physically and emotionally drained. His only company is a robot, 'Gerty' (voiced by Kevin Spacey) and the plants he has nurtured with care. He has had enough. It is time to go home. We are shown images of his wife and child and their video messages sent from Earth. We see that he has built personal relationships with inanimate objects to combat his loneliness. He displays and craves empathy and human touch. He is utterly 'human'. He is wearing clothing that is 
clearly from his home on earth. Petrie's design of Sam's limited and highly personal wardrobe infers that he would have carefully chosen each item, the garments appear fetishized performing as 'charms' (Pearce 1994: 199), loaded with meaning that might connect him with his life on Earth. He has a T-shirt with the slogan 'Wake me up when it's quitting time', a well-worn Hawaiian shirt, a pair of comfy slippers and a cap worn and marked by his constant touch as habit or comfort or both. His workwear in contrast is impersonal and utilitarian. Sam1's lonely but simple world implodes when he crashes his rover out on the moon surface, caused by a strange and impossible hallucination. It leads him to discover he is in fact a clone. Gerty, believing Sam1 to be dead, awakens a replacement clone, 'Sam2'. The two clones meet and all that Sam1 and Sam2 have been programmed to believe to be true of their lives is taken away. Costume is instrumental in helping the viewer understand the plot, and the contrast between the two characters in their accelerated passage from birth to death (the clones having an inbuilt lifespan of 3 years before being incinerated). Their costume of an identical wardrobe in contrasting levels of breakdown reflect their physical and mental states, offering a useful opportunity for comparison of the affects that breakdown might have on the haptic visuality of the textiles. The 'memories' as with Marx's coat, are at once integral to our understanding and visual reading of Sam1, and stark by their absence in the newly awakened Sam2.

Costume breakdown adds 'meaning to the matter' (Mazis 1996 in Barker 2009: 2). Barker in her book The Tactile Eye quotes Glen Mazis' summary of Merleau-Ponty's explanation of the 'general meaningfulness of matter' (Mazis 1996). The thing is given a 'manner of being...what Merleau-Ponty calls "style", (Mazis 1996). Breaking down the structure of the cloth makes the 'properties' (Mazis 1996) of the thing more discernible as a discourse between the film and its audience. In Moon the sense of wear, the grime and gritty grey Moon dust that performs as a visual reminder of the environment outside the stark walls of the base's interior and the drying blood on Sam1's t-shirt, all 'have an accent, and atmosphere' (Mazis 1996). Much of the character of the wearer emerges through the 'style' of the breakdown. The signifiers offered in the marks made and treatment of the cloth can trigger audience's everyday associations with personal and perceived 'memories'(Stallybrass:133), as well as offering a deeper understanding of the world that the character inhabits. This might stimulate a non-verbal conversation and an emotional alignment where: - '[b]oth perceived and perceiver are joined in that style of intercourse from which their identity emerges' (Mazis 1996). Jane Petrie describes her own approach to costume breakdown: - 'I try to find 
memories, emotions and journeys made before the character arrives on our screen, and to show it in their clothing, as well as the obvious decisions they would make in response to things like weather or class or occupation' (Petrie, personal communication, 2017). Petrie believes that the points of reference displayed on Sam's clothing must perform within the confines of the script, allowing the ideas to 'come off the page' rather than impose them herself. 'Not applying onto, but getting into the fibres themselves. I want the history to come through the clothes, not sit on top' (Petrie, personal communication, 2017). In my own experience of viewing the film I can see Petrie representing the various states of mental and physical breakdown in Sam1 through the fibres of the cloth, stimulating my eye to dive into the properties of the textiles themselves, the warp and the weft of the interwoven fibres highlighted or obscured by the brushstrokes of the textile artist.

Claire Pajaczkowska's paper 'On Stuff and Nonsense' (Pajączkowska, 2005) brilliantly extends Deleuze's hypothesis of the fold to articulate our rich and often complicated relationship with cloth. Deleuze explored the characteristics of multi-layered Baroque thinking which 'def[ied] the previous $\left[14^{\text {th }}\right.$ to $17^{\text {th }}$ Century $]$ Renaissance concept of a single linear plane of human and ecclesiastical experience which he described as 'monocular subjectivity' (Pajączkowska 2005: 224). Baroque thought represents a sense experience which 'engulfs and envelops' as the folds in cloth, individual in their nature, some hidden from view but concurrently connected to many other such layers (Pajączkowska 2005: 224). Following Pajaczkowska, my approach aims to assess the particular folds and layers of visual affects that the textiles might have on the viewer's gaze. Applying Deleuze's hypothesis, I believe these affects do not function in a linear form of unfolding temporality, but as folds within folds of thoughts, experiences, memories and textures which can be experienced concurrently, randomly and iteratively. What is happening between these folds? I suggest that each sensation stimulated by the haptic visuality of the cloth performs within the folds as Deleuze posits: - '[N]ot [as] sensations of different orders, but different orders of one and the same sensation' (Deleuze 2005;2003: 37), and the further the audience are drawn into the folds, the deeper those sensations within those folds envelope and are sensed (Deleuze : 37), the 'image [made] more immediately real' (Deleuze: 37). A phenomenological experience within the folds of the viewer's body, to the screen, to the textures of cloth and flesh of the actor and back again. 


\section{The Gaze}

Vivian Sobchack asserts that there are four visual stages, all pre-reflexive, that describe the 'maturation of cinematic vision in which the visual becomes visible, seeing becomes seen, and perception is reversibly commuted to expression' (Sobchack: 22). The image, having been projected onto the screen at 'point zero' (Sobchack: 22), comes to the second stage where the attention of the camera has been placed on particular objects or people by the camera zoom, the third is where our attention rests upon those objects, and the fourth is the movement of the camera (Sobchack: 22). It is at the third stage that I would argue the affects of costume breakdown come into focus, but as yet meaning has not been made of what the viewer's gaze has fallen upon. We see the objects but we do not 'notice' them (MerleauPonty, Landes 2013: 7). I suggest that costume breakdown stimulates the viewer to linger on the object, the viewer's gaze is drawn through the screen, they are 'experiencing sensations more somatic than cerebral' (Merleau-Ponty, Landes: 7).

This nascent view of the textile is seen in abstract, the gaze of the viewer, as Pajaczowska explains 'understood as infantile and unconscious, imply[ing] a different kind of subject and a different relationship of the subject to the rational' (Pajaczkowska: 226). The haptic visuality can engender feeling as the nature of the object stimulates the brain to become conscious and attempts to assess what Merleau-Ponty describes as 'qualities' (MerleauPonty, Landes: 7). Returning to Deleuze's analogy of the fold (Pajaczkowska: 224) and Bacon's assertion that the same sensation exists in different orders (Deleuze: 37), I propose that it is possible to identify three (nonlinear) stages of reading in this phenomenological experience. Accepting that the viewer is engaged, their senses will weave back and forth almost instantaneously between the three depending on visual texture, focus, framing, narrative, lighting and the emotional states of the character, different surfaces of the experience laid against one another.

A primary stage of visual experience, being pre-symbolic, focuses on the properties of the cloth. The way we encounter the film haptically, makes what we see 'sensible' (MerleauPonty, Landes: 7). As Merleau-Ponty explains '[t]he visible is what is seized on with the eyes, the sensible is what is seized on by the senses' (Merleau-Ponty, Landes: 7). Pajaczkowska believes that ' $[\mathrm{t}]$ he obscurity of the pre-symbolic is complicated and fascinating' (Pajaczkowska: 245). A useful focus may be through the lens of Deleuze's 
theory of rubrics, and our quest for meaning from the abstract. What is the logic of the sensations that we feel when we first encounter the image depicted? (Slack 2005: 132). '[W]here in wonder, frustration, or disgust we find ourselves unable to answer with familiar satisfaction, "what does it mean?"' (Slack: 131). In this instance we see moving images that are part of the narrative, we understand where Sam has come from and why he looks a certain way. But what do we feel about the textured cloth as abstract set before us? As we experience sensation triggered by the haptic visuality of the cloth, I suggest that we quickly, or concurrently, come to another stage where the cloth emits an aura, it becomes volatile with the sensory meaning the viewer has attributed to it. This meaning, performing as a gesture, seizes the audience and guides them towards an embodied and symbolic understanding of the narrative as 'form' (Barthes, Lavers 1972: 128), informed by personal associations of myth reliant on habitus that fetishizes the experience. This stage will not be analysed, but as a surface to the fold it works in constant relay with the abstract and auratic folds of sensual experience that curve back into the fabric of the viewer's embodied experience of the film.

\section{$\underline{\text { Sensation }}$}

Costume breakdown can have similar properties to that of sound in rapprochement and relache of the audience, bringing them in harmony with the film or releasing their gaze from its hold. Marks explains that 'sound operates along a dialectic similar to that of haptic and opticality' (Marks 2000: 182). She explains that 'we listen for specific things, while we hear ambient sound as an undifferentiated whole' (Marks: 183). Tonalities of the breakdown performing as the 'tonalities' of sound, felt before they are evaluated, the viewer's gaze is arrested and drawn in to linger on a detail which may have been glanced over. The tonalities of the texture and colour, the weight and the wear of the fabric, the rough next to the smooth, vitally the way the light is absorbed in or bounces away from the fabric, casting light on the skin or drawing the eye into the darkness all stimulate sensation, allowing the audience to sense the 'qualities' of the fabric (Merleau-Ponty, Landes: 4).

What is felt will not determine whether a viewer is engaged, but it is important that there is a feeling. Following Merleau-Ponty, I suggest that a 'perceiving subject' will view the costumes with 'feeling' and judge if 'an object looks attractive or repulsive before it looks black or blue, circular or square' (Merleau-Ponty, Landes: 4). As with a patch of colour painted onto a background '[e]ach part arouses the expectation of more than it contains, and 
this elementary perception is therefore already charged with meaning' (Marks: 4). The viewer is drawn to find meaning from that 'patch' whilst at the same time perceiving the 'field' (Marks: 4) in which it sits, it cannot be, and is not intended to be viewed in isolation.

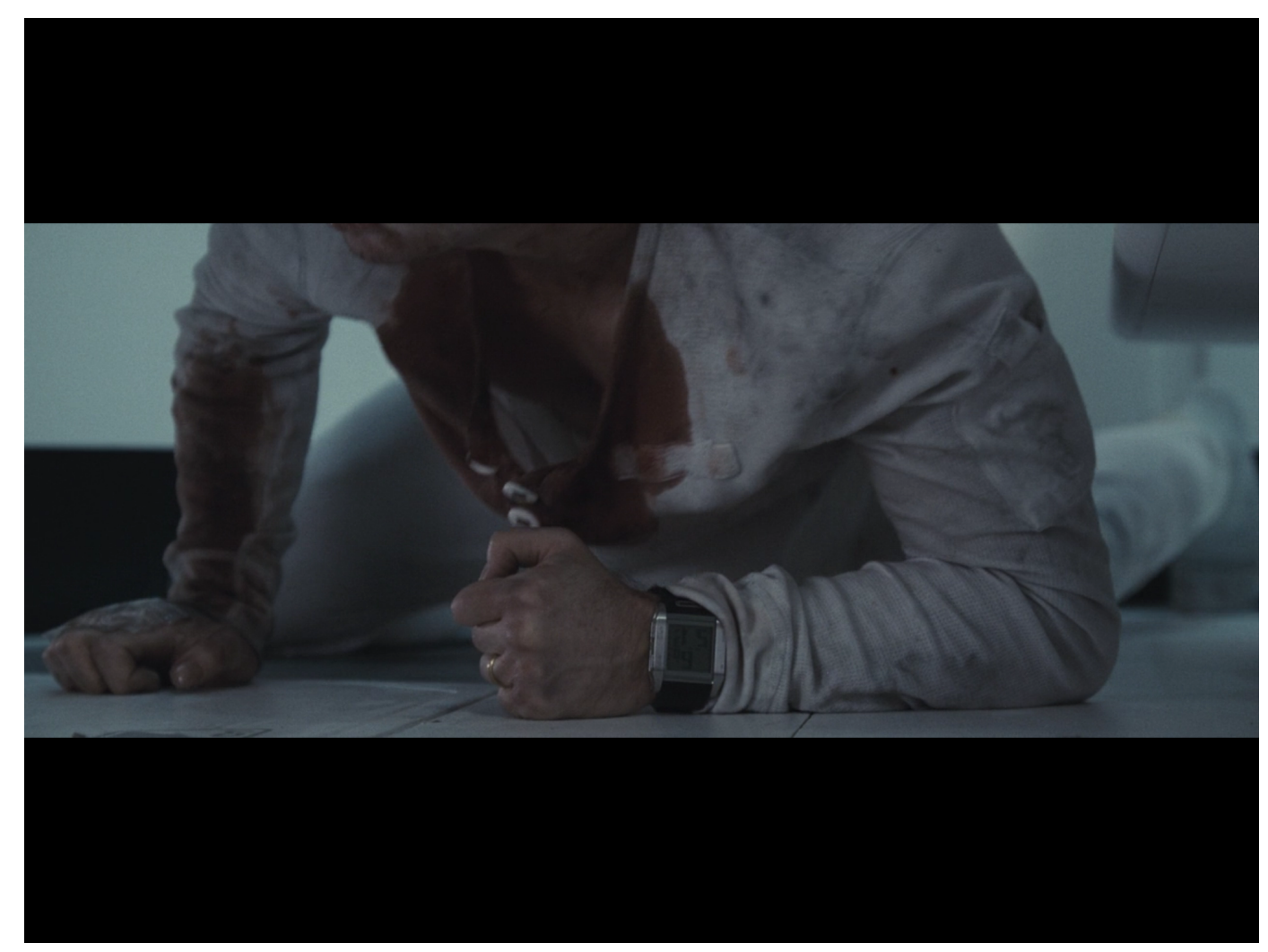

Figure 2: Screen grab taken from Moon (2009) (C Liberty Films/Lunar Industries/ SPWA 2009.

This still of 'Sam 1' (Fig. 2) is taken from a scene where he is desperately searching for evidence of other clones on the base, his mental and physical state close to collapse.

Accepting that the image would not normally be seen in this way, in isolation from what has come before and what is to come after, the audience's gaze has been drawn in by the close framing of the camera, illustrating the third stage of cinematic vision as described by Sobchack. The viewer's gaze performs as an 'arresting gaze' a 'meaningful gaze' (Sobchack: 24) that Sobchack explains is not passive but always 'introspectively, subjectively busy: at work prospecting its world' (Sobchack: 24), trying to find meaning from the patch brought into focus by time, framing the haptic qualities of the fabric (Marks: 162). This frame gives principal emphasis to the textures, folds and qualities of the fabric, as Marks explains, 'privileg[ing] the material presence of the image' (Marks: 162). Here we see soft folds, light and shade, dirt and grime and blood that works in stark contrast to the bright white hard and 
shiny buttons. The viewer's exploratory gaze, the 'haptic looking...mov[ing] over the surface of the... [cloth], not to distinguish form so much as to discern texture' (Marks: 162), allowing the qualities of the surface to be abstracted from the whole, as Jennifer Slack explains, we are freed from the subject and story (Slack: 132). This freedom allows the sensations offered by the haptic visuality of the art of costume breakdown to be felt.

Jennifer Slack's essay on Deleuze's work: Francis Bacon: The logic of Sensation, explores his analyses of the "“rubrics" or "aspects" of Bacon's paintings, how his brushstrokes and composition, his 'practice of painting without telling a story... accesses sensation that exceeds meaning and representation' (Slack: 133). Slack explains that,

[R]ubric asserts a sensation, an intensity, a "colouration". Rubrics "givens" that converge in a logic of sensation, are always already sensations with intensities; they are coloured, textured, flavoured, shaped; they are always already "accumulated" or “coagulated" "sensation" (Slack: 134).

The brushstrokes that the textile artist applies to the cloth, in this instance the dark grey matt Moon dust, the deep red drying blood and the fabric that has been worn to expose some of the warp and the weft of its materiality, are rubrics that bring the inside of Sam's body out onto the surface, these textures and colours have corporeal meaning, engendering an embodied sensation through touching with our eyes. The marks are there on his clothes because of the narrative, but the visceral effect of pre-symbolic sensation engendered by the rubrics of the breakdown, allows the audience to 'experience the sensation' (Slack: 134). As Slack outlines this allows the viewer to " "enter" the event, live the sensation in the body, [and] become the sensation' (Slack: 136). These sensations once experienced by the nervous system, through the haptic visuality stimulated by the interplay of vision and light, texture and embodiment, will quickly begin to act in relay with the folds of meaning that might be stimulated by these sensations, to imbue the textiles that we are gazing on with an aura.

\section{Aura and Gesture.}

Laura Marks suggests that haptic images are 'a subset of what Deleuze referred to as optical images: those images are so "thin" and un-clichéd that the viewer must bring his or her resources of memory and imagination to complete them' (Marks: 163). I would argue that it 
would be at this point the viewer would attribute the cloth being observed and in consequence the person whose skin is touching that cloth, with a certain aura, it becomes performative in discourse with the audience. Benjamin 'wrote that aura is the quality in an object that makes our relationship to it like a relationship with another human being. It seems to look back at us' (Benjamin 1968: 188). Benjamin believed aura is lost by the lack of physical presence of the performer as we would find in the cinema. He claimed that 'aura is tied to presence; [and] that there can be no replica of it' (Benjamin, Arendt, 1992: 231). My thesis is that as Alice through the looking glass, we can climb through the cinema screen and feel the presence of Sam1 by touching with our eyes.
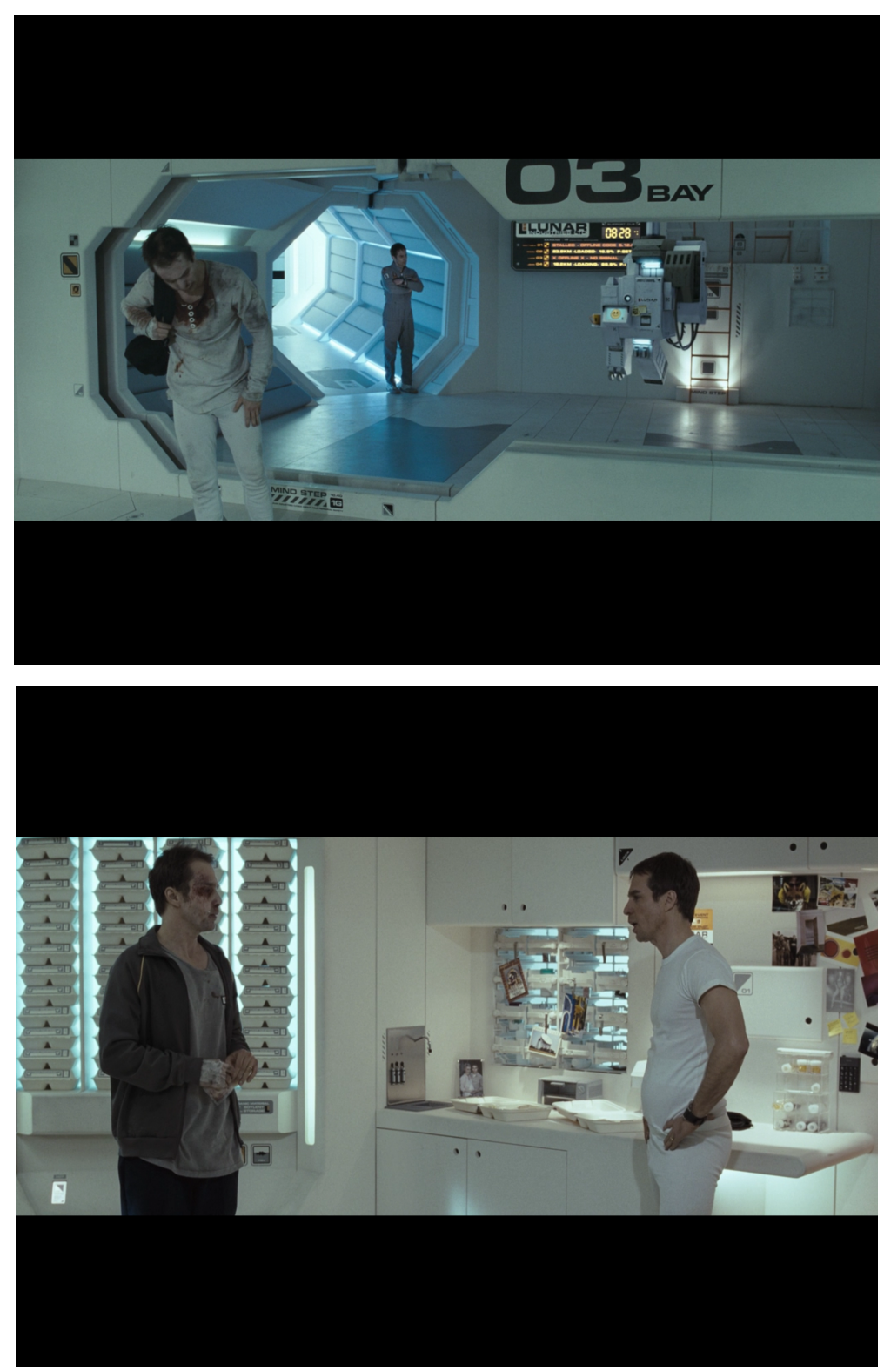

Figure 3-4: Screen grab taken from Moon (2009) (C) Liberty Films/Lunar Industries/ SPWA 2009. 
These stills (Fig.3 and Fig.4) offer an opportunity to assess the effects that costume breakdown can have on the audience by contrasting its presence with its absence, its influence on the rapprochement and relache of the viewer's gaze and therefore sensations of touch that emit or diminish the character's aura. This is not in reference to the possible feeling of repulsion a viewer might have for the blood and other bodily fluids that are bringing Saml's insides out in Fig.4, but the affect of the presence or absence of any texture or detail on which the gaze might be drawn. If we knew nothing of the narrative that has brought these two (albeit) identical men into the same shot, our gaze would still be held longer on Sam1 than Sam2. As a narrative construct, the contrasting breakdown of the two character's costumes in Fig.3, and Fig. 4 is an effective strategy. We are being asked to empathise more with the dirtied and dyeing clone Sam1, than the newly awakened 'box fresh' clone Sam2. However, I suggest that no matter where Sam1 is positioned in the shot, we are drawn to him by our ability to touch him with our eyes. The gaze is drawn and arrested, there is sensation triggered by the state of his clothing, bloodied and dirty, rumpled and worn, absorbing light, we have an embodied experience of his internal self. Conversely, Sam2 repels us by the lack of visual stimuli, in both stills his costume is stark, reflecting light, clean and devoid of texture. I would argue that in Sam1 we sense an aura that is not apparent in Sam2.

The sensations triggered by the rubrics of the costume breakdown, using Benjamin's analogy of the surgeon and the magician (Benjamin and Arendt: 235), allows the viewer's gaze to 'penetrate' the film and the body of the actor. Our imaginations are aroused, performing between and onto the folds of the viewer's sensual experience, transforming 'feelings, intentions, and the "bodiless" reality of thoughts into images of motion' (Sobchack: 22). The broken down cloth, imbued with an aura, becomes ever more volatile on the screen, and within the folds of sensation performs as a 'gesture'. Our gaze feels that something is being said and we ask what that might be? Sobchack quotes Yvette Biro's description of a gesture's function. Gesture: -

[T]ransforms feelings, intentions and the "bodiless" reality of thoughts into images of motion. It lends them sensory form while it remains the mysterious intermediary: providing us only with points of reference in order to help us round out the missing information, arousing empathy and firing our imagination (Sobchack: 22). 
The thingness of the cloth stimulates an awareness of the thingness of the body, both ours and Sam 1's, performing as folds within folds of our relationship with the characters on screen. Well before the finished film reaches the audience however, I would suggest that the affects of costume breakdown might even be performing as gestures 'on-set', and could have the power to influence the very tempo and artistic composition of a film sequence. The gestures influencing the first eye to focus its contemplative gaze on the scene, that of the camera lens commanded by the vision of the director.

\section{The Director as Audience}

In Moon we see that Duncan Jones often asks the camera to linger on certain aspects of the costume. One particular example (figures. 5\&6) is his apparent attraction to the detailing of the astronaut's cap, with its strong resonance of a medieval coif. ${ }^{i}$ Of course as a costume this functions to protect an astronaut's head from the helmet, and there could be narrative reasons for the symbolism of the coif, his appearance at times reminiscent of a lone monk or a filthy serf. But my own gaze, in what are lengthy shots of the back of his head, is always drawn to the lacing on that coif.

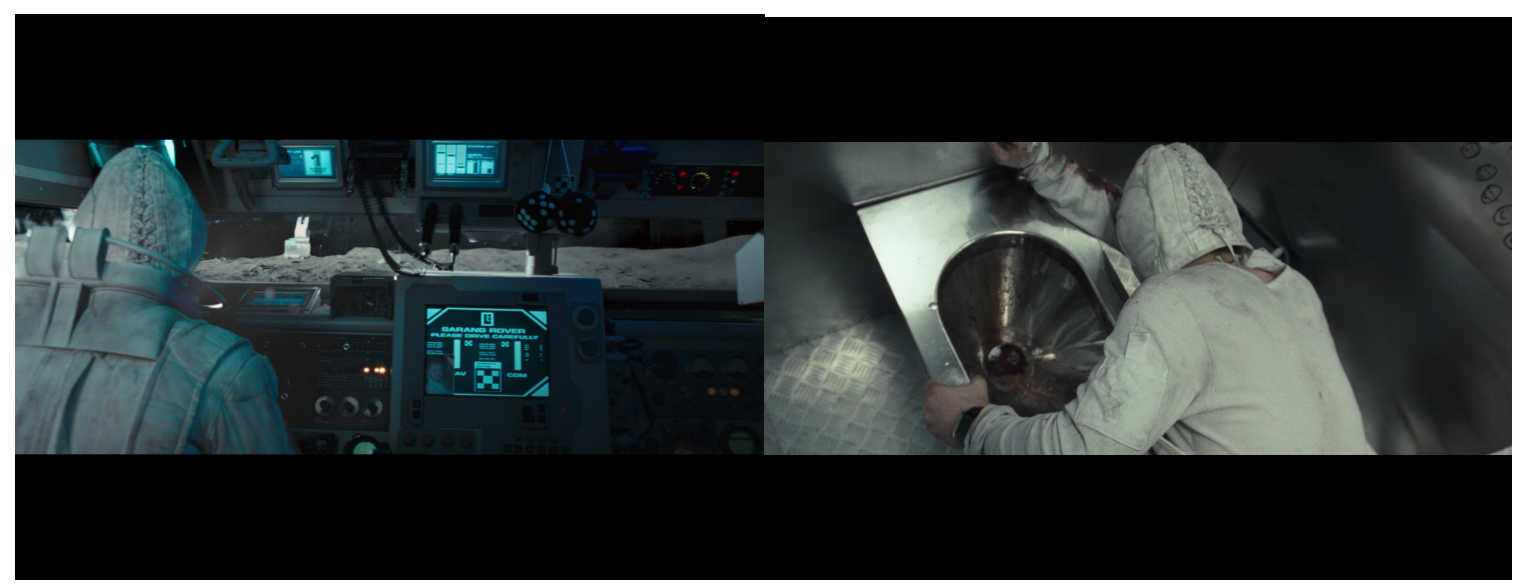

Figures 5-6: Screen grab taken from Moon (2009) (C) Liberty Films/Lunar Industries/ SPWA 2009.

Merleau-Ponty articulates how directors are instinctively shooting and editing to certain 'cinematic rhythms' (Merleau-Ponty 1964: 54), knowing when the shot is complete, not necessarily dictated by dialogue or action, and not necessarily in a position to consciously 'formulate the rules which he spontaneously obeys' (Merleau-Ponty 1964: 54). Handling 'cinematographic language as a man manipulates syntax' (Merleau-Ponty 1964: 55). The 
textile artist, in this instance Petrie, provides rich visual texture that performs as a gesture, 'fire[ing] the [director's] imagination' (Merleau-Ponty 1964: 55). The detailing arrests the gaze with its pleasing criss-cross pattern, highlighted by the shading of the Moon dust and soft texture of the cords woven together. The cords pull the fabric of the coif around the back of his head, acting as a gesture that creates a feeling of security. The back of the head, not normally an interesting place to linger becomes alive with meaning by the presence of the treated textile, drawing the audience into Sam1's internal cerebral world.

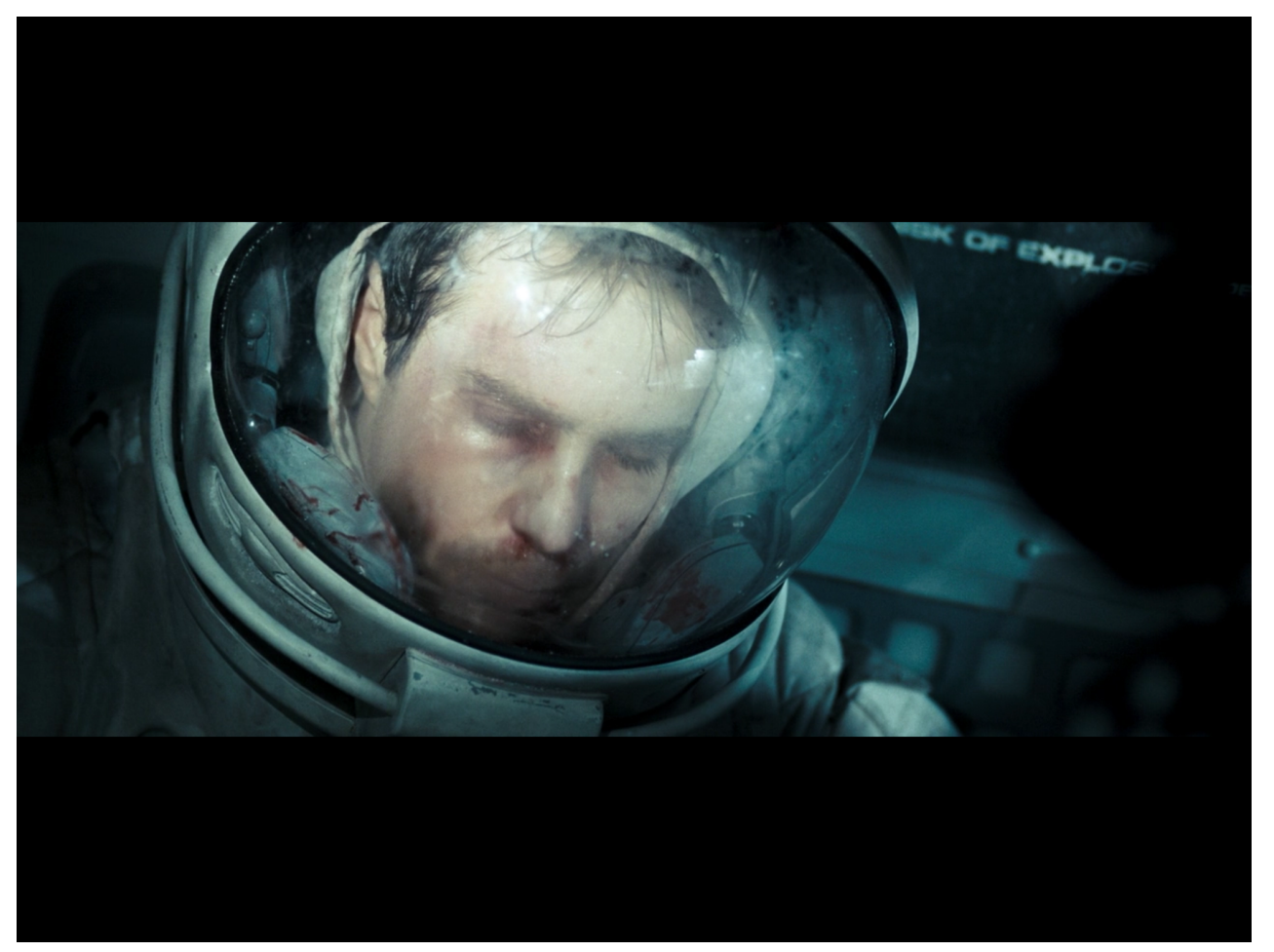

Figure 7: Screen grab taken from Moon (2009) (C) Liberty Films/Lunar Industries/ SPWA 2009.

Here Sam1 (Figure 7), is close to death. In this image again we can feel the coif, framing his face, cradling his head like a pair of hands. Through the apparent barriers of the cinema screen, through the hard material of his visor, we feel the energy of the fabric in close proximity to the waxy flesh of his skin, the wrinkles in the seams and binding draw us in. He is alone in his final moments, but held by the embodied empathetic gaze of the audience. 


\section{Conclusion}

Sensory scholarship of the phenomenological affects that costume breakdown as a textile art might have on an audience, offers an opportunity to enhance the already rich scholarship of film, costume, haptic visuality and our embodied relationships with visual culture. The art is one of many ways that films might perform discursively, but one that I believe has not been sufficiently acknowledged as an integral part of the intertextuality that informs successful film design in general. I believe that encouraging film and costume practitioners to explore the value of costume breakdown because of its relationship to the body, might offer a way of regaining some of the performer's aura that, as Benjamin asserts, is lost by the mechanical intervention of the film camera.

The rubrics of the various forms of textile art can add visual depth and meaning as well as a deeper connection with the characters in the film. As a form of escapism or as a tool to communicate a new way of seeing, there is opportunity for creating even richer embodied experiences through the use of textile art to draw the viewer through the barrier that the screen creates. The art of costume breakdown, when applied appropriately and artfully, asks the viewer's gaze to pause and pay attention to a particular moment, a particular patch, a particular fold. By pausing, the viewer explores the haptic visuality of that moment, actively creating a new sense experience and an embodied connection with the character on the screen, drawing the viewer further into the folds of the film. As Sobchack asserts '[i]n sum, the film experience is meaningful not to the side of our bodies but because of our bodies' (author's emphasis) (Sobchack 2004: 60). 
Post script:

Since writing this paper I am delighted to have been introduced to an article by anthropologist Clare Wilkinson and textile artist Anthea Mallinson 'Making Time: A Conversation on Aging Film Costumes' (2017) written for Drain Magazine.

Their conversation, in my opinion, offers readers an enlightening consideration of the 'craft' (Mallinson, Wilkinson, 2017: 2) of the textile artist charged with the role of breaking down a costume for film.

Describing the breakdown artist as an 'artisan' (Mallinson, Wilkinson: 2), Mallinson outlines the intuitive approach these artists take to the costume. To study a piece of work Mallinson suggests we might 'lift' (Mallinson, Wilkinson: 2) the garment out of its intended context in order to contemplate the aesthetic beauty of the artist's work in isolation. They suggest that a skilled artist possesses an implicit understanding of the visual language required to communicate a character's personal narrative through their art, the well-crafted broken down costume offering a 'reading' that accounts for aesthetic and cultural expectations of the costume designer, director, actor and audience.

I would encourage anyone less familiar with costume breakdown, having read their piece, to return to my paper, as I feel our thoughts, woven together, work in harmony to offer a deeper understanding of the importance of this particular textile art, and with that hopefully encourage further study into the art of costume breakdown and its importance to the visual culture of film. 


\section{References}

Arnold, Andrea. (2009) Fish Tank, United Kingdom: UK Film Council, Kasander Film Company, Limelight Communication, Content Film.

Barthes, R. \& Heath, S. (1977), Image, music, text, Fontana, London.

Barthes, R. \& Lavers, A. (1972), Mythologies, Cape, London.

Benjamin, W. \& Arendt, H. (1992), 'On Some Motifs in Baudelaire' Illuminations, Fontana, London, in Marks, L.U. 2000, The skin of the film: intercultural cinema, embodiment, and the senses, Duke University Press, Durham, N.C.

Benjamin, W. \& Arendt, H. (1992), 'The Work of Art in the Age of Mechanical Reproduction' Illuminations, Fontana, London.

Bruzzi, S. (1997), Undressing cinema: clothing and identity in the movies, Routledge, London.

Deleuze, G. (2003), 'Painting and Sensation' Francis Bacon: the logic of sensation, Continuum, London.

Gavron, S. (2015) Suffragette, United Kingdom: Film 4, BFI, Ingenious Media, Canal+, Ruby Films.

Jones, D. (2009) Moon, United Kingdom: Liberty Films, Xingu Films, Limelight.

Gaines, J. \& Herzog, C. (1990), Fabrications: costume and the female body, Routledge, New York;London.

Grosz, E. (1994), Volatile bodies: toward a corporeal feminism, Indiana University Press, Bloomington.

Mallinson, A, Wilkinson, C. (2017) 'Making Time: A Conversation on Aging Film Costumes' Drain, drainmag.com/making-time-a-conversation-on-aging-film-costumes/. Accessed 6 September 2017.

Marks, L.U. (2000), The skin of the film: intercultural cinema, embodiment, and the senses, Duke University Press, Durham, N.C.

Mazis, G.'Matter, Dream and the Murmurs among things', in Merleau-Ponty: Difference, Materiality,Painting.(1996) (Ed.) Veronique M.Foti Humanities Press International, NJ. pp76 in Barker M. (2009) The Tactile Eye: Touch and the Cinematic Experience. University of California Press, London.

Merleau-Ponty, M. (1964) 'The Film and the New Psychology' in Sense and non-sense, Northwestern University Press, Evanston, Ill.

Merleau-Ponty, M. \& Landes, D.A. (2013), Phenomenology of perception, Routledge, London.

Pajaczkowska, C. (2005) "On stuff and nonsense: The complexity of cloth", Textile, vol. 3:3, pp. 220-248.

Pearce, S. (1994) Interpreting Objects and Collections, Routledge: London. 
Petrie, J. (2017) Jane Petrie Costume Design. http://janepetrie.com/. Accessed 21 April 2017.

Petrie, J. (2017) personal email communication, 13 March.

Slack, J D.'Logic of Sensation’ Stivale, C.J. (2005), Gilles Deleuze: key concepts, Acumen, Chesham.

Sobchack, Vivian. (1990) 'The Active Eye: A Phenomenology of Cinematic Vision'. Quarterly Review of Film \& Video, Vol 12:3. Harwood Academic Publishers: USA, 1990. Journal.

Sobchack, V. (2004), 'What my fingers knew' Carnal thoughts: embodiment and moving image culture, University of California Press, Berkeley, Calif;London;.

Stallybrass, P. 'Fetishizing Commodities, Fetishizing Things' in Spyer, P. (1998), Border fetishisms: material objects in unstable spaces, Routledge, New York;London.

Stoller, P. (1997), Sensuous scholarship, University of Pennsylvania Press, Philadelphia.

\footnotetext{
i For further information on Medieval Coifs see Singman, J. (1999) Daily Life in Medieval Europe, pp.42-43, Greenwood Press, Conneticut;London.
} 